\title{
PPM LENTO MBOK GEDE PADA BUMDES SUN GEDE MAKMUR DI DESA SUMBERGEDE KECAMATAN WRINGINANOM KABUPATEN GRESIK
}

\author{
Andri Krisna Dianto1, Dwiyana Anella Kurniasari², Yurifar Burhanudin ${ }^{3}$, Meylinda Thirta \\ Arlina $^{4}$ \\ Universitas Wijaya Putra Surabaya
}

andrikrisna@uwp.ac.id , dwiyanaanela@uwp.ac.id, joesandy309@gmail.com, thirtaaarlina@gmail.com

\begin{abstract}
Abstrak
Sun Gede Makmur adalah Badan Usaha Milik Desa (BUMDes) di Desa Sumbergede Kecamatan Wringinanom Kabupaten Gresik. BUMDes Sun Gede Makmur memiliki produk olahan makanan tradisional yaitu Lento dengan nama produk Lento Mbok Gede. Permasalahan yang dihadapi oleh mitra yakni (1)belum memiliki strategi pemasaran online. (2) kemasan (Packaging) kurang menarik sehingga penjualan produk Lento Mbok Gede kurang. (3)Proses Produksi selama ini masih belum memiliki Standar produksi. Berdasarkan hal tersebut metode yang digunakan adalah Pelatihan dan Pendampingan guna memberikan solusi pada permasalahan mitra yakni (1) Pelatihan dan Pendampingan pembuatan akun online shop. (2) kemasan baru (Upgrade Packaging) yang lebih menarik produk Lento Mbok Gede. (3) Merumuskan dan pembuatan Buku Standard Operating Procedure (SOP) Proses Produksi Lento Mbok Gede untuk meningkatkan hasil produksi yang memiliki kualitas yang sama. Hasil dari pengabdian masyarakat ini, (1) Sun Gede Makmur telah memiliki akun online shop dengan nama LentoMbok. (2) Lento Mbok Gede memiliki packaging baru dengan tampilan lebih menarik, (3) Sun Gede Makmur memiliki SOP Proses Produksi Lento Mbok Gede.
\end{abstract}

Kata Kunci : BUMDes, Strategi Pemasaran, SOP Produksi Lento

\section{PENDAHULUAN}

Badan Usaha Milik Desa (BUMDes) merupakan instrumen pemberdayaan ekonomi lokal dengan berbagai ragam jenis usaha sesuai dengan potensi yang dimiliki desanya. Pengembangan potensi ini memiliki tujuan untuk meningkatkan kesejahteraan ekonomi warga desa melalui pengembangan usaha ekonomi. Disamping itu, keberadaan BUMDes juga membawa dapak terhadap peningkatan sumber pendapatan asli desa (PAD) yang memungkinkan desa untuk mampu melakukan sebuah pembangunan dan juga untuk peningkatan kesejahteraan secara lebih optimal. BUMDes sebagai badan hukum, dibentuk berdasarkan tata perundangundangan yang berlaku, dan sesuai dengan aturan yang berlaku di desa. Dalam Undang- undang Nomor 32 Tahun 2004 tentang Pemerintah Daerah pada Pasal 213 ayat 1-3 disebutkan bahwa desa dapat mendirikan Badan Usaha Milik Desa (BUMDes) sesuai dengan kebutuhan dan potensi desa. Sesuai dengan aturan tersebut, pembentukan BUMDes didasarkan atas kebutuhan dan potensi yang dimiliki desa, dengan tujuan sebagai upaya peningkatan kesejahteraan masyarakat.

BUMDes ini merupakan badan usaha yang seluruh atau sebagian besar modalnya dimiliki oleh desa melalui penyertaan secara langsung yang 
berasal dari kekayaan desa yang dipisahkan guna mengelola aset, jasa pelayanan, dan usaha lainnya untuk sebesar-besarnya kesejahteraan masyarakat (Pradani, 2020)

Dalam hal ini perencanaan dan pembentukannya, BUMDes dibangun atas inisisai masyarakat desa, serta mendasarkan pada prinsipprinsip kooperatif, partisipatif, dan emansipatif. Hal yang paling penting adalah bahwa pengelolaan BUMDes harus dilakukan secara profesional, kooperatif, dan mandiri. Dengan demikian, bangun BUMDes dapat beragam di setiap desa di Indonesia. Sehubung dengan itu, maka untuk membangun BUMDes diperlukan informasi yang akurat dan tepat tentang karakteristik kelokalan termasuk ciri sosial budaya masyarakat.(Adawiyah, 2018)

Namun adanya pandemi covid-19 melanda membuat keadaaan BUMDes yang ada saat ini menjadi tidak berjalan sebagaimana mestinya tentu hal ini berbanding terbalik dengan harapan pemerintah pusat maupun pemerintah daerah bahwa Badan Usaha Milik Desa (BUMDes) bisa menjadi ujung tombak perekonomian desa. Terutama di tengah upaya pemerintah melakukan pemulihan ekonomi usai pandemi covid-19 melanda. keberadaan BUMDes harus mampu mengangkat ekonomi masyarakat desa. Hal ini juga dialami oleh BUMDes Sun Gede Makmur di desa Sumbergede Kecamatan Wringinanom Kabupaten Gresik yang memiliki usaha produksi dan penjualan Kuliner tradisional yang berfokus pada produk unggulan desa yaitu Lento Mbok Gede.

Namun setelah adanya pandemic covid-19 ini kegiatan produksi dan pengelolaannya terhenti karena beberapa faktor diantaranya penurunan penjualan akibat dari PSBB adalah singkatan dari Pembatasan Sosial Berskala Besar, peraturan yang diterbitkan Kementerian Kesehatan (Kemenkes) dalam rangka Percepatan Penanganan COVID-19 agar bisa segera dilaksanakan di berbagai daerah. Aturan PSBB tercatat dalam Peraturan Menteri Kesehatan Nomor 9 Tahun 2020 Yang pada akirnya juga berpengaruh pada berubahnya Strategi Pemasaran (Putsanra, 2021).

Pemasaran merupakan alat fundamental yang direncanakan untuk mencapai tujuan perusahaan dengan mengembangkan keunggulanbersaing yang digunakan untuk melayani pasar (Diniaty, 2014).
Strategi pemasaran adalah suatu system keseluruhan dari kegiatan usaha melalui perencanaan, penentuan harga, mempromosikan, dan mendistribusikan barang dan jasa yang memuaskan dan memenuhi kebutuhan pembeli (Atmoko, 2018). Proses pemasaran adalah proses tentang bagaimana perusahaan dapat memasarkan produk atau mempengaruhi konsumen, agar para konsumen bisa membeli produk yang ditawarkan dan akhirnya konsumr menjadi puas sehingga mereka akan selalu membeli produk perusahaan itu, dan perusahaan tidak akan pernah kehingan pangsa pasar atau konsumen sehingga produk itu terus laku dipasaran (Rusdi, 2019).

Menghadapi lingkungan dan kondisi yang berbeda tentu hal ini berimbas pada pemasaran Lento Mbok Gede yang belum memiliki strategi pemasaran yang sesuai dengan kondisi kekinian. Maka dalam hal ini kami beserta tim bermaksud untuk melakukan kegiatan PPM Lento Mbok Gede Pada Bumdes Sun Gede Makmur Di Desa Sumbergede Kecamatan Wringinanom Kabupaten Gresik dengan harapan dapat menghidupkan kembali usaha produksi dan pemasaran yang baik serta penggunaan strategi pemasaran yang tepat untuk keberlanjutan produk unggulan desa Lento Mbok Gede.

\section{METODE}

Pemberdayaan kepada masyarakat PPM Lento Mbok Gede Pada Bumdes Sun Gede Makmur Di Desa Sumbergede Kecamatan Wringinanom Kabupaten Gresik dalam pelaksanaannya dibagi dalam 4 (Empat) tahapan kegiatan yaitu pada tahap pertama dilakukan dengan Pelatihan dan Pendampingan pembuatan akun online shop (Shopee, Instagram dan Tokopedia) atau Market Place lainnya. Tahap kedua dilakukan dengan Pembuatan kemasan baru (Upgrade Packaging) yang lebih menarik produk Lento Mbok Gede. Tahap ketiga Merumuskan dan pembuatan Buku Standard Operating Procedure (SOP) Proses Produksi Lento Mbok Gede untuk meningkatkan hasil produksi yang memiliki kualitas yang sama dan tahap keempat dilakukan Evaluasi hasil dari keseluruhan program BUMDes Sun Gede Makmur. 


\section{HASIL DAN PEMBAHASAN}

\section{Deskripsi BUMDes Sun Gede Makmur}

Kuliner tradisional di Indonesia memiliki banyak sekali keanekaragaman, terutama dalam hal kuliner tradisional. Setiap daerah memiliki makanan khas yang menjadi produk unggulan dari daerah tersebut. Mitra dalam Program Pemberdayaan Masyarakat ini adalah Badan Usaha Milik Desa (BUMDes) Sun Gede Makmur Desa Sumbergede Kecamatan Wringinanom Kabupaten Gresik.

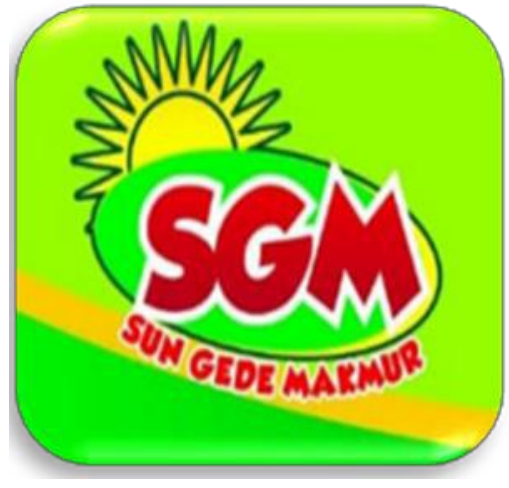

Gambar 1. Logo BUMDes Sun Gede Makmur

BUMDes Sun Gede Makmur yang di pimpin oleh Bapak Sholihuddin yang ada di Desa Sumbergede memproduksi makanan khas lento dengan nama produk Lento Mbok Gede. Awal mula produksi kuliner khas desa Sumbergede ini merupakan kolaborasi dari 8 industri rumahan di Desa Sumbergede yang membuat produk olahan berupa Lento. Produk Olahan dinamakan Lento Mbok Gede karena yang membuat adalah si mbokmbok atau ibu-ibu desa setempat dengan postur tubuh yang besar (Gede). Kata gede juga memiliki makna tersendiri yakni Generasi Desa. Yang membuat Lento ini berbeda dengan lento yang lain adalah ukuran dan tekstur nya. Bentuk nya yang besar (Gede) dan tekstur nya yang renyah membuat lento ini punya cita rasa tersendiri bagi penikmat kuliner tradisional. (Makmur, 2021). Launching produk olahan Lento Mbok Gede dilakukan pada tanggal 28 November 2019.

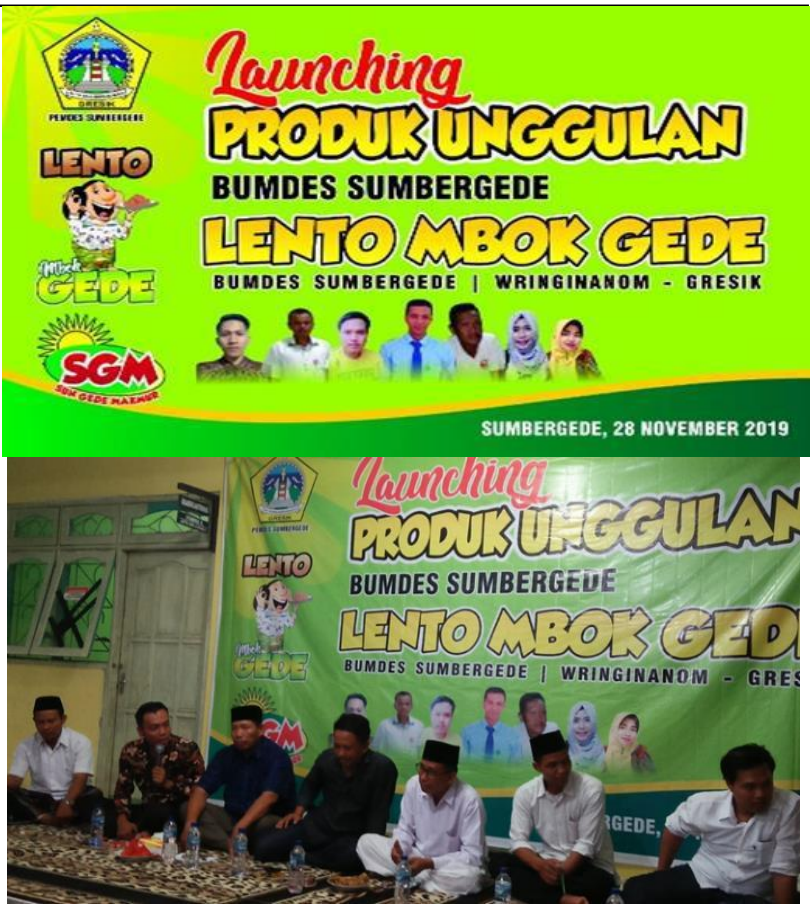

Gambar 2. Launching Lento Mbok Gede

Dalam manajemen persediaan bahan baku, pihak BUMDES bekerjasama dengan mitra selain itu bahan baku diperoleh dari pasar. Proses produksi Lento Mbok Gede di dilakukan oleh 18 orang dengan tugas dan porsi masing-masing Proses produksi Lento, dilakukan 3 kali dalam 1 minggu. Dalam satu kali proses produksi Lento Mbok Gede menghasilkan 2800 butir. Sehingga dalam waktu satu minggu proses produksi Lento Mbok Gede sebanyak 8400 butir.

\section{Hasil PPM lento Mbok Gede}

Pelatihan Dan Pendampingan Pembuatan Akun Online Shop 
Pada tahap pertama PPM ini dilakukan dengan Pelatihan dan Pendampingan pembuatan akun online shop. Dalam kegiatan ini dilakukan dengan pemilik dan pengurus inti dari $\mathrm{CV}$ sun gede makmur. Hasil dari pelatihan dan pendampingan ini adalah terciptanya akun online shop yaitu Facebook (Lento Mbok Gede) dan Instagram (lento_mbokgede).

Gambar akun facebook lento mbokgede
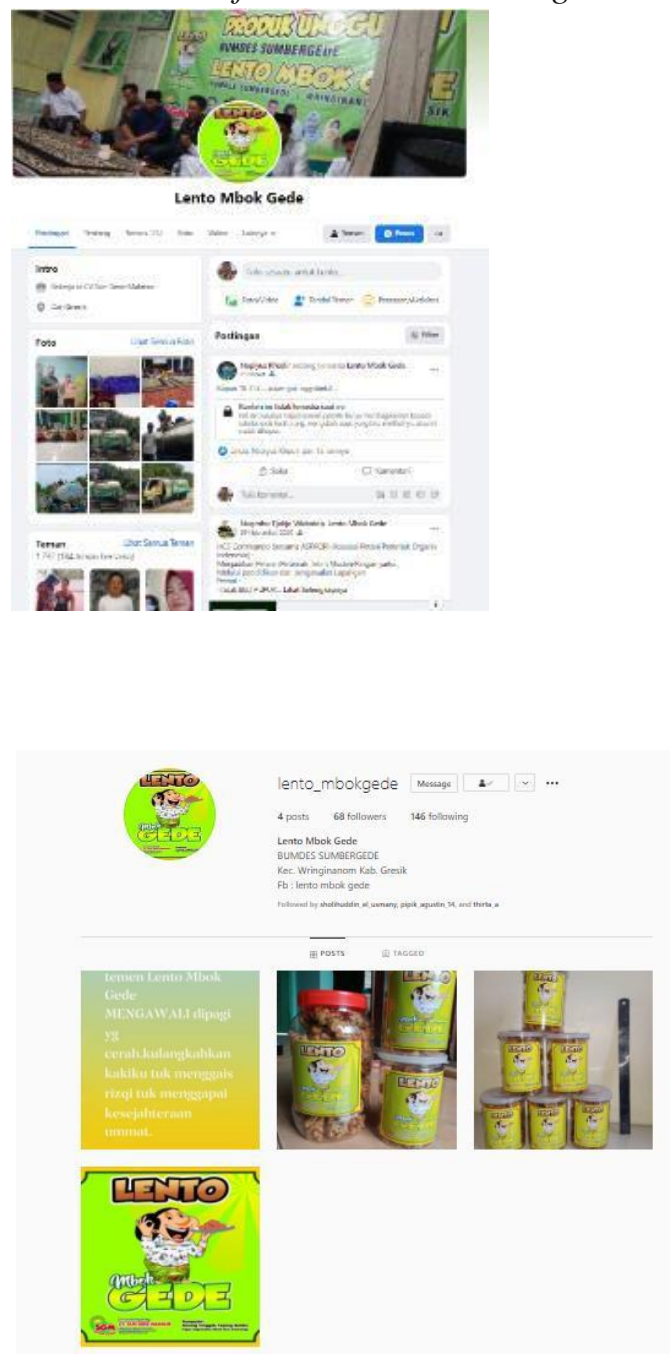

Gambar akun instagram lento_mbokgede

Dengan adanya akun akun online shop yaitu Facebook (Lento Mbok Gede) dan Instagram (lento_mbokgede) diharapkan akan menambah tingkat penjualan dari Lento Mbok Gede.

\section{Kemasan Baru (Upgrade Packaging)}

Tahap kedua dari PPM dilakukan dengan Pembuatan kemasan baru (Upgrade Packaging) yang lebih menarik produk Lento Mbok Gede. Karena dalam kondisi saat ini kemasan juga menjadi hal yang diperhatikan konsumen.
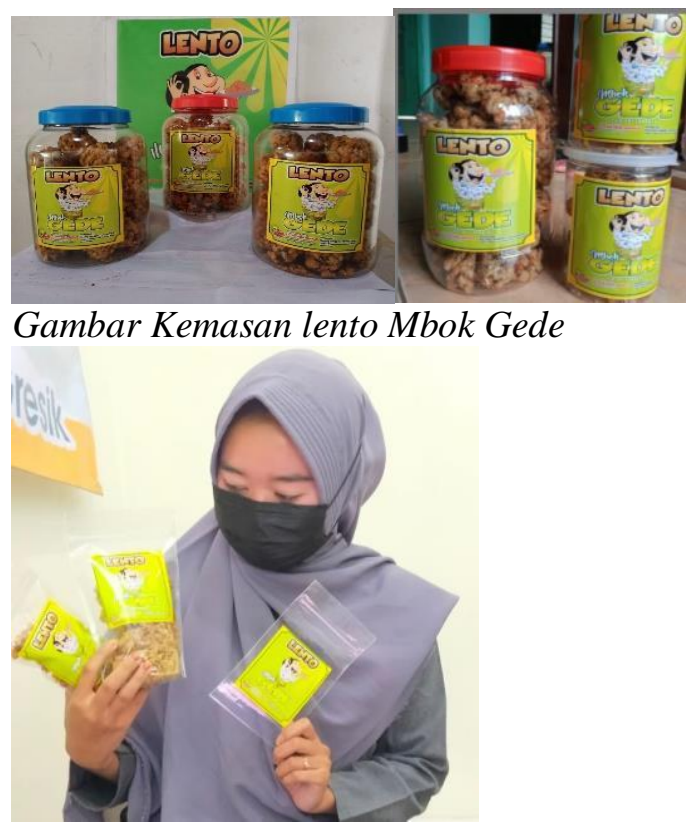

Gambar Kemasan Baru lento Mbok Gede

Semakin menarik kemasan sebuah produk juga akan mempengaruhi minat beli dari konsumen. Dengan adanya kemasan baru diharapkan juga akan lebih menarik konsumen untuk membeli Lento Mbok Gede.

\section{Pembuatan Merumuskan dan pembuatan Buku Standard Operating Procedure (SOP) Proses Produksi Lento Mbok Gede}

Tahap ketiga Merumuskan dan pembuatan Buku Standard Operating Procedure (SOP) Proses Produksi Lento Mbok Gede untuk meningkatkan hasil produksi yang memiliki kualitas yang sama. 


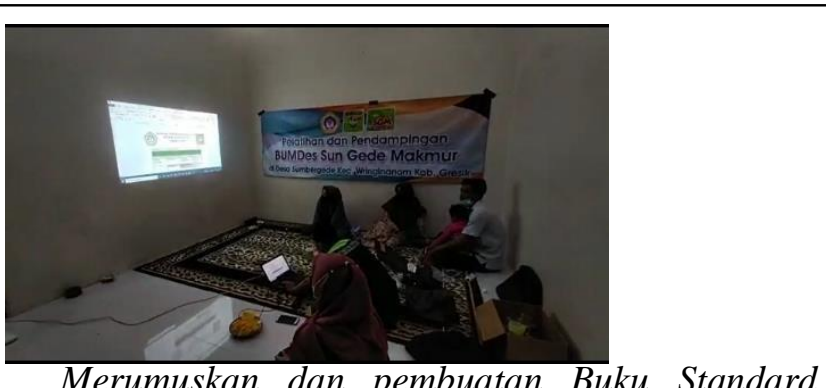
Operating Procedure (SOP) Proses Produksi Lento Mbok Gede

Dengan adanya SOP diharapkan Produsen Lento mbok gede bisa menjaga kualitas dari lento yg diproduksi dengan ukuran dan kualitas yang sama.

\section{Evaluasi hasil dari keseluruhan program BUMDes Sun Gede Makmur}

Tahap keempat dilakukan Evaluasi hasil dari keseluruhan program PPM Lento Mbok Gede pada BUMDes Sun Gede Makmur.

Dari evaluasi hasil dari keseluruhan program PPM Lento Mbok Gede pada BUMDes Sun Gede Makmur, mitra merasa terbantu dengan adanya Program Pemberdayaan Masyarakat ini yang memberikan pengetahuan dan pelatihan yang sangat berguna dalam pengembangan dan peningkatan dari usaha kuliner tradisional khususnya Lento Mbok Gede.

Rekomendasi kegiatan selanjutnya adalah diperlukan pendampingan ulang untuk pengembangan produk seperti variasi produk dan varian rasa produk serta perlu pendampingan dan penambahan karyawan khusus media sosial yang akan bertanggung jawab untuk menjadi admin dalam menangani online shop Lento Mbok Gede.

\section{KESIMPULAN}

PPM Lento Mbok Gede ini dengan Pelatihan dan Pendampingan guna memberikan solusi pada permasalahan mitra dan memiliki hasil sebagai berikut : (1) Sun Gede Makmur telah memiliki akun online shop dengan nama LentoMbok. (2) Lento Mbok Gede memiliki packaging baru dengan tampilan lebih menarik, (3) Sun Gede Makmur memiliki SOP Proses Produksi Lento Mbok Gede.
Diperlukan pendampingan tentang pengembangan produk dan penambahan karyawan guna menjadi admin dari Online shop milik Lento Mbok Gede pada kegiatan selanjutnya.

\section{UCAPAN TERIMAKASIH}

Ucapan terimakasih disampaikan kepada Bapak Sholihuddin sebagai Ketua dan staff administrasi BUMDes Sun Gede Makmur. Serta Tim Dosen dan mahasiswa PPM Lento Mbok Gede Pada Bumdes Sun Gede Makmur Di Desa Sumbergede Kecamatan Wringinanom Kabupaten Gresik.

\section{REFERENSI}

(Adawiyah, 2018)Atmoko, T. P. (2018). Strategi Pemasaran Untuk Meningkatkan Volume Penjualan Di Cavinton Hotel Yogyakarta. Ournal Of Indonesian Tourism, Hospitality And Recreation, 83-96.

Diniaty, D. (2014). Perencanaan Strategi Pemasaran Pada Produk Anyaman Pandan. Jurnal Sains, teknologi dan industri, 175-184.

Makmur, B. S. (2021, April 12). Lento Mbok Gede. Diambil kembali dari Lento Mbok Gede: https://lentombokgede.blogspot.com/2020/0 1/lento-mbok-gede.html

Pradani, Rizki F.E. 2020. Pengembangan Badan Usaha Milik Desa (BUMDes) Berbasi Potensi Lokal Sebagai Penggerak Ekonomi Desa. Jurnal Economic and Policy Studies. Vo. 1 No. 1. 14-23

Putsanra, D. V. (2021, April 14). Arti PSBB yang Dibuat untuk Cegah Penyebaran Corona di Indonesia. Diambil kembali dari Tirto.id: https://tirto.id/arti-psbb-yang-dibuat-untukcegah-penyebaran-corona-di-indonesiaeMXT

Rusdi, M. (2019). Strategi Pemasaran Untuk Meningkatkan Volume Penjualan Pada. Jurnal Studi Manajemen dan Bisnis, 49-54. 